\title{
Evaluating the psychometric properties of the attitudes towards depression and its treatments scale in an Australian sample
}

This article was published in the following Dove Press journal:

Patient Preference and Adherence

2I April 2012

Number of times this article has been viewed

Fadia Isaac'

Kenneth Mark Greenwood ${ }^{2}$

Mirella Di Benedetto 3

'Cairnmillar Institute School of Psychology Counselling and Psychotherapy, Camberwell, Victoria, Australia; ${ }^{2}$ School of Psychology and Social Science Faculty of Computing, Health and Science, Edith Cowan University, Joondalup, Western Australia, Australia; ${ }^{3}$ School of Health Sciences, Royal Melbourne Institute of Technology University, Bundoora, Victoria, Australia
Correspondence: Ken Greenwood School of Psychology and Social Science, Faculty of Computing, Health and Science, Edith Cowan University, 270 Joondalup Drive, Joondalup,

WA 6027, Australia

Tel +6I 863042769

Fax +6I 863045015

Email k.greenwood@ecu.edu.au
Background: Individuals' attitudes towards depression and its treatments may influence their likelihood of seeking professional help and adherence to treatment when depressed. Objective measures, such as the Attitudes Towards Depression and its Treatments scale (ATDT), have been developed to assess such attitudes. The aims of this research were to test the reliability and validity of ATDT on an Australian sample who were not depressed during the study or who had previously been depressed, to explore the attitudes of the Australian public towards depression, and to compare these attitudes to those of a Canadian sample of people with depression.

Methods: A sample of 63 males and 140 females (mean age $=32.2$ years, SD $=12.9$ years) from Melbourne, Australia took part in this study. Fourteen of the males and 52 of the female participants (mean age $=35.4$ years, $\mathrm{SD}=13.2$ years) stated that they had been previously diagnosed with depression.

Results: The attitudes of the Australian sample and the subset of that sample who had previously experienced depression differed from those of the Canadian outpatient sample: they were less ashamed of depression, more likely to take antidepressants and consider psychotherapy, and more likely to seek help from professionals or significant others in their lives. However, those in the Australian sample were more likely to report that antidepressants made them lose control, and they were less willing to consider electric shock as a treatment option for their depression. The internal reliability as measured by Cronbach's alpha was lower in the current study $(0.63$ and 0.57 for both the general public and the depressed Australian sample) than in the Canadian study. Confirmatory factor analysis failed to replicate the factor structure reported previously. Limitations: The Australian sample of this study may be underrepresentative due to the sampling methods used, and the high proportion of females should not be overlooked.

Conclusion: Researchers should be vigilant when utilizing measures constructed in different countries. In comparison to the Canadians, the selected Australian sample had more positive attitudes towards depression and its available treatments. The ATDT scale was not a reliable and valid measure in this sample.

Keywords: attitudes, depression, objective measures, psychometric properties

\section{Introduction}

Depression is a global issue, with consequences that are both economically and socially significant. ${ }^{1,2}$ Research suggests that by the year 2020 depression will be the second most important cause of disability worldwide. ${ }^{3}$ However, around $50 \%$ of those with major depression do not seek professional help, ${ }^{4-8}$ and it has been argued that stigma is a major contributor to this..$^{9,10}$ Furthermore, research suggests that personal attitudes, such as the belief that health professionals are unsupportive, viewing depression as a weakness of character, or the belief that medications are harmful, are also important 
predictors of avoiding professional help. ${ }^{11,12}$ In addition, patients' own beliefs about the causes of their depression are important in understanding their needs and providing effective treatment. ${ }^{13}$ Research has revealed that belief in biological causes of depression is correlated with confidence in pharmacological treatments and seeking professional help. ${ }^{14}$ Conversely, Australian researchers found that those who believed that depression is caused by social or environmental factors (specifically stressors) were more likely to prefer self-help and nonpharmacological treatments. ${ }^{15}$

Beliefs such as stigma, the causes of depression, its treatments, and seeking psychological help are important factors in understanding attitudes towards depression and its treatments. As such, personal attitudes may have a negative effect on both initiation and adherence to treatment. ${ }^{16,17}$ The failure to initiate and adhere to treatment may have substantial consequences such as longer duration of the illness, longer lasting psychosocial difficulties, occupational and interpersonal impairments and, most importantly, increased suicide rates. ${ }^{18,19}$

In Australia, vignettes are the dominant means of recognizing and identifying depression. Research shows that only $50 \%$ of participants (from a study where $\mathrm{N}=900$ ) were able to differentiate depression from sadness when presented with vignettes. ${ }^{15}$ The Attitudes Towards Depression and its Treatments scale (ATDT) was developed to address the scarcity of objective measures reported in the literature, using a sample of 63 Canadian outpatients with nonpsychotic depression. ${ }^{17}$ Unlike vignettes, the items included in the ATDT target many domains such as causes of depression, available treatments, and help-seeking behavior. A group of psychiatrists determined the appropriateness, clarity, and relevance of the items to test attitudes towards depression (88\% agreement). The internal consistency reliability (Cronbach's alpha) reported for the full-scale ATDT was 0.79. An exploratory factor analysis yielded five subscales: acceptance of treatment, perceived stigma and shame, negative attitude towards antidepressants, self-stigma, and preference for psychotherapy. It has been concluded that the ATDT is a reliable and a valid measure, and researchers have called for future work to replicate and extend these results with larger and more heterogeneous samples. ${ }^{17}$

Therefore, the present study aimed to further test the psychometric properties of the ATDT. The attitudes of community samples are likely to be more relevant to treatmentseeking than the attitudes in an outpatient sample, so this was also examined. Furthermore, the majority of work on this topic in Australia has focused on the study of community samples where recognition of depression is achieved via the presentation of vignettes rather than the utilization of objective measures. $^{20,21}$

\section{Method \\ Participants}

Sixty-three Australian males and 140 females aged from 18 to 77 years $(\mathrm{M}=32.2, \mathrm{SD}=12.9)$ participated in the survey. Some $48.8 \%$ of participants identified themselves as single, $31.5 \%$ were married, $16.7 \%$ were in a de facto relationship, and $3 \%$ were widowed or separated. Their highest education level varied, with $1 \%$ having completed primary school, $41.1 \%$ secondary school, $16.8 \%$ having a diploma, $25.7 \%$ an undergraduate degree, and $15.3 \%$ a postgraduate degree.

Fourteen males and 52 females, with a mean age of 35.4 years $(\mathrm{SD}=13.2)$, stated that they had been diagnosed at some time with depression by a health professional (psychiatrist, psychologist, or general medical practitioner). Of these 66 participants, 62 stated that they either had received, or were still receiving, treatment for their depression, with $24.6 \%$ receiving antidepressants, $14.8 \%$ receiving psychotherapy, $57.4 \%$ receiving both psychotherapy and antidepressants, and $3.3 \%$ receiving some other kind of treatment. Thirteen individuals (19.7\%) stated that they had had one episode of depression, nine (13.6\%) reported two episodes, and 44 (66.7\%) reported having had three or more episodes.

\section{Measures}

\section{Demographics}

Information was obtained on participants' age, sex, ethnic background, marital status, education level, previous diagnosis of depression, whether there were receiving/had received treatment for depression, and the type of treatment.

\section{Attitudes towards depression and its treatments scale}

Following the advice of A Gabriel (personal communication, April 8, 2010), the present study utilized 25 items taken from the original 27-item ATDT scale (see Table 1). Two items (original item 7, "I feel stigmatized being diagnosed with depression", and original item 17, "People of my culture do not allow me to take antidepressants") were removed and the remaining 25 items were numbered sequentially. The items were divided into four subscales: patient's attitude to the illness, attitude to biological treatments, attitude to 
Table I Means (standard deviations) for each item on the attitudes towards depression scale for the present sample $(n=203)$ and the sample reported on by Gabriel and Violato ${ }^{17}(n=63)$ with the results of $t$-tests comparing the samples

\begin{tabular}{|c|c|c|c|c|c|}
\hline \multirow[t]{2}{*}{ Item } & \multicolumn{2}{|l|}{$M(S D)$} & \multirow[t]{2}{*}{$t$} & \multirow[t]{2}{*}{$p$} & \multirow[t]{2}{*}{$d$} \\
\hline & Present Sample & Gabriel and Violato & & & \\
\hline I. Depression is a legitimate medical disorder & $4.2(1.0)$ & $1.4(1.0)$ & 20.02 & 0.001 & 2.86 \\
\hline 2. I think that depression is a weakness of character & $1.9(1.0)$ & $2.4(1.6)$ & -2.97 & 0.003 & -0.37 \\
\hline 3. Depression is due to being mentally ill & $2.9(1.1)$ & $3.1(1.5)$ & -1.15 & 0.250 & -0.15 \\
\hline $\begin{array}{l}\text { 4. I think that depression could be due to a chemical imbalance } \\
\text { in the brain }\end{array}$ & $3.8(0.9)$ & $1.7(1.2)$ & 15.20 & 0.001 & 2.00 \\
\hline 5. Depression is just due to feeling sorry for oneself & $2.0(1.0)$ & $2.3(1.4)$ & -1.88 & 0.060 & -0.25 \\
\hline 6. I cannot tell anyone that I suffer from depression & $2.4(\mathrm{I} . \mathrm{I})$ & $2.5(1.4)$ & -0.59 & 0.550 & -0.08 \\
\hline 7. I am not alone; many others suffer from depression & $4.2(0.8)$ & $1.7(1.0)$ & 19.69 & 0.001 & 2.70 \\
\hline 8. People avoid talking to me because I am depressed & $2.3(1.0)$ & $2.4(1.4)$ & -0.63 & 0.530 & -0.08 \\
\hline 9. People in the community see me as dangerous & $1.7(0.9)$ & $2.2(1.7)$ & -2.98 & 0.003 & -0.36 \\
\hline 10. I feel less ashamed, since I learned more about the illness & $3.3(1.1)$ & $2.1(1.3)$ & 7.23 & 0.001 & 0.99 \\
\hline II. I would not take antidepressants as a first line of treatment & $2.7(1.0)$ & $2.7(1.6)$ & 0.00 & 1.00 & 0.00 \\
\hline 12. Psychiatric medications are harmful & $3.5(1.3)$ & $2.0(1.3)$ & 2.66 & 0.008 & 0.38 \\
\hline $\begin{array}{l}\text { 13. I will consider antidepressants only if my symptoms are } \\
\text { out of control }\end{array}$ & $3.5(1.1)$ & $3.5(1.7)$ & 0.00 & 1.00 & 0.00 \\
\hline 14. Antidepressants are habit-forming & $2.5(1.0)$ & $2.3(1.3)$ & 1.32 & 0.180 & 0.17 \\
\hline 15. Antidepressants make me lose control & $3.5(1.0)$ & $1.9(1.2)$ & 10.56 & 0.001 & 1.45 \\
\hline 16. I will take antidepressants, if my doctor is confident about them & $3.6(1.3)$ & I.7 ( 1.0$)$ & 10.65 & 0.001 & 1.64 \\
\hline $\begin{array}{l}\text { 17. I will not accept Electric Shock Treatment for my depression even } \\
\text { if it is necessary }\end{array}$ & $4.1(1.0)$ & $3.1(1.4)$ & 6.26 & 0.001 & 0.82 \\
\hline 18. I will consider psychotherapy as a first choice for my depression & $3.5(1.0)$ & $2.8(1.4)$ & 4.38 & 0.001 & 0.57 \\
\hline 19. I prefer psychotherapy in combination with my antidepressants & $3.5(1.1)$ & $2.0(1.1)$ & 9.46 & 0.001 & 1.36 \\
\hline $\begin{array}{l}\text { 20. I believe that psychotherapy, or "talk therapy", is always useful } \\
\text { on its own }\end{array}$ & $2.0(1.1)$ & $2.6(1.2)$ & -3.70 & 0.003 & -0.52 \\
\hline 21. I prefer to see my family physician if I feel depressed & $3.0(1.1)$ & $4.0(1.3)$ & -6.02 & 0.001 & -0.83 \\
\hline 22. I would ask to see a psychiatrist if I am depressed & $3.2(1.1)$ & $1.8(1.0)$ & 9.01 & 0.001 & 1.33 \\
\hline 23. Psychiatrists are not really helpful for depressed persons & $2.3(0.9)$ & $2.0(1.4)$ & 2.04 & 0.042 & 0.26 \\
\hline 24. I will seek help from a psychiatrist if I have doubt about medication & $3.6(0.9)$ & $1.7(1.2)$ & 13.08 & 0.001 & 1.76 \\
\hline $\begin{array}{l}\text { 25. I would seek help for my depression only from significant others } \\
\text { in my life }\end{array}$ & $2.5(1.1)$ & $2.0(1.3)$ & 3.01 & 0.002 & 0.42 \\
\hline
\end{tabular}

psychological treatment, and attitude and perceptions to professional help. The items are scored on a 5-point Likert scale (from $1=$ strongly agree to $5=$ strongly disagree). Apart from an exploratory factor analysis and assessment of internal consistency, little is known about the properties of the scale. ${ }^{17}$ However, replicating the factor structure and internal consistency in a different sample was a good first step before additional measurement properties were assessed.

\section{Procedure}

Following approval by the Royal Melbourne Institute of Technology University Ethics Committee, participants were recruited via several methods in an attempt to obtain a large and more representative sample. Participants were approached in community centers and were offered a sealed envelope containing the questionnaires. A snowball sampling technique was also utilized by circulating emails about the study. An online version of the survey was distributed by the researchers to personal and academic contacts who were asked to invite others to participate. The study was advertised at a few medical centers, community churches, advertisement boards at the Royal Melbourne Institute of Technology University, by word of mouth, and on the beyondblue National Australian Depression Initiative website. ${ }^{22}$ Participants were asked to read a plain language statement and give consent, and had the option of completing questionnaires on paper or online. Participants were recruited from September 2010 until February 2011. While the sample may not be representative, the variety of sampling methods employed achieved the aim of a larger and more heterogeneous sample.

\section{Results}

Table 1 shows the mean and standard deviation of responses to each of the 25 items alongside those reported in Canada by 
Gabriel and Violato. ${ }^{17}$ Independent samples $t$-tests revealed significant differences between the Australian sample and the sample of depressed individuals from Canada for 18 items of the ATDT. Items 1, 4, 7, 10, 15, 16, 17, 19, 21, and 24 displayed large effect sizes (Cohen's $d>0.8) .{ }^{23}$ In general, those in the Australian sample had more positive attitudes towards depression and its treatments than Canadians on items 1, 4, 7, 10, 16, 19, 21, and 24. However, Australian participants (depressed and nondepressed) had more negative attitudes for items 15 and 17, in that Australians were more likely to think that antidepressants make them lose control and were less willing to consider electric shock as a treatment option for their depression.

As Gabriel and Violato used a sample of individuals with depression, comparisons were also made with the subset of the present sample that had been diagnosed as depressed. A similar pattern of results was found, with significant differences between the Canadian and the Australian sample with depression seen for 18 items (items 1, 4, 7, 10, 16, 18, 19, 21, 22, and 24 with large effect sizes). Those in the Australian subsample had more positive attitudes than Canadians on all of these items, except item 21 (Australians were less willing to see a family physician when feeling depressed).

Table 2 shows the internal consistency reliability (Cronbach's alpha) of the total scale and its subscales for both the Australian sample and the depressed subsample, and for the depressed sample reported in Canada. ${ }^{17}$ The Cronbach's alpha values for the current study were much lower than those reported by Gabriel and Violato: for the full sample, the largest value of alpha that was obtained was 0.65 , and for the depressed subsample, the largest value was only 0.57 .

The internal consistency analyses indicated that the ATDT scale did not share the same factor structure as reported

Table 2 A comparison of Cronbach's alpha for the ATDT subscales and the total scale for the present sample $(n=203)$, the subsample who reported having received a diagnosis of depression $(n=66)$ and the sample reported on by Gabriel and Violato $(n=63)$

\begin{tabular}{llll}
\hline Scale & $\begin{array}{l}\text { Present } \\
\text { sample } \\
(\boldsymbol{n}=\mathbf{2 0 3})\end{array}$ & $\begin{array}{l}\text { Depressed } \\
\text { subsample } \\
(\boldsymbol{n}=\mathbf{6 6})\end{array}$ & $\begin{array}{l}\text { Gabriel and } \\
\text { Violato (2009) } \\
(\boldsymbol{n}=\mathbf{6 3})\end{array}$ \\
\hline ATDat & 0.65 & 0.41 & 0.76 \\
ATDpss & 0.42 & 0.38 & 0.76 \\
ATDnaa & 0.50 & 0.49 & 0.78 \\
ATDss & 0.06 & 0.01 & 0.64 \\
ATDpp & 0.18 & 0.32 & 0.58 \\
Total scale & 0.63 & 0.57 & 0.79 \\
\hline
\end{tabular}

Abbreviations: ATDat, acceptance of treatment; ATDpss, perceived stigma and shame; ATDnaa, negative attitude towards antidepressants; ATDss, self stigma; ATDpp, preference for psychotherapy. by Gabriel and Violato. This was confirmed by the use of confirmatory factor analysis using AMOS and maximum likelihood estimation. The independence model tests the hypothesis that all variables are unrelated and was easily rejected $(C M I N=1296.51 ; P<0.001)$. However, the model proposed by Gabriel and Violato was also rejected $(C M I N=776.52$; $P<0.001, C M I N / \mathrm{df}=2.93)$. Other fit statistics also provided little support for the model (eg, CFI $=0.487$, TLI $=0.419$, RMSEA $=0.098$ ). Consistent with the internal consistency analyses, some limited support was found for the ATT subscale where seven of the eight items proposed to load on the factor had significant but small regression weights. However, support for the other subscales was minimal.

\section{Discussion}

The current study revealed significant differences between the attitudes of Australians and Canadians towards depression and its treatments. This result was unexpected.

The Australian subsample had more positive attitudes towards depression than the Canadian sample, in that Australians were less ashamed of depression, and were more likely to:

- think that depression is a legitimate medical disorder,

- think that depression could be due to a chemical imbalance in the brain,

- think that many others suffer from depression,

- take antidepressants if their doctors are confident about them,

- consider psychotherapy as the first choice of treatment for their depression,

- consider a combination of psychotherapy and antidepressants,

- believe that psychotherapy is always useful on its own,

- see a psychiatrist if feeling depressed,

- seek help from a psychiatrist if in doubt about medication, and

- seek help from significant others in their life for depression.

Conversely, the Australian sample was:

- more likely to think that antidepressants make them lose control,

- less likely to consider electric shock as a treatment option even if necessary,

- less likely to see a family physician when feeling depressed, and

- less likely to think that psychiatrists are helpful for a depressed person.

Interestingly, the observed differences persisted when comparing the two depressed samples - a similar pattern 
of positive attitudes was seen for the Australian sample, although the depressed Australian subsample was less likely to see a family physician if feeling depressed.

The reason for the difference in attitudes between the two samples is unknown. One would expect that the two cultures might be similar. The differences could be due to the homogeneity of the Canadian sample, all of whom were diagnosed with depression and undergoing treatment at the same center. Another possible explanation is the pioneering work that has been undertaken in Australia by organizations such as beyondblue and the Black Dog Institute to publicize and educate the public about depression. ${ }^{24,25}$ It is also possible that the sample of Australians in this study could be biased despite the use of multiple sampling strategies.

A reliability analysis revealed that the ATDT is not a reliable measure in the present sample. Furthermore, the factor structure reported in Canada was not replicated in the Australian sample. These findings suggest that new measures should be validated before use in different countries.

An obvious limitation of this study is the extent to which the sample can be representative due to the sampling methods employed. The large sample size, the varied sampling methods, and the variability of demographic characteristics suggest some degree of representativeness of the wider population, unlike the Canadian sample. However, until replication takes place this remains uncertain and any conclusions should be viewed with some caution. Furthermore, the high proportion of females should not be overlooked.

Without broader replication of the factor structure and improvements in the internal consistency of the ATDT, it seems premature to assess other psychometric properties such as test-retest reliability, precision, and acceptability.

In conclusion, the ATDT was not found to be a reliable measure in this Australian sample. However, such measures are lacking and more efforts are needed to establish reliable and valid tools as they have the potential to assist health professionals to select appropriate treatments that are consistent with individuals' attitudes. Furthermore, such tools could also be utilized to promptly assess any negative attitudes that individuals may hold, allowing health care professionals the option of educating patients or modifying their attitudes prior to commencing treatment.

\section{Acknowledgments}

The authors wish to thank Dr Adel Gabriel who kindly provided a copy of the ATDT scale to be used in this research.

\section{Disclosure}

The authors report no conflicts of interest in this work.

\section{References}

1. Pincus HA, Pettit AR. The societal costs of chronic major depression. J Clin Psychiatry. 2001;62 Suppl 6:5-9.

2. Simon GE. Social and economic burden of mood disorders. Biol Psychiatry. 2003;54(3):208-215.

3. Murray CJ, Lopez AD. Alternative projections of mortality and disability by cause 1990-2020: Global Burden of Disease Study. Lancet. 1997;349(9064):1498-1504.

4. Blumenthal R, Endicott J. Barriers to seeking treatment for major depression. Depress Anxiety. 1996-1997;4(6):273-278.

5. Fisher LJ, Goldney RD. Differences in community mental health literacy in older and younger Australians. Int J Geriatr Psychiatry. 2003;18(1):33-40.

6. Henderson JG Jr, Pollard CA, Jacobi KA, Merkel WT. Help-seeking patterns of community residents with depressive symptoms. $J$ Affect Disord. 1992;26(3):157-162.

7. Lauber C, Carlos N, Wulf R. Lay beliefs about treatments for people with mental illness and their implications for antistigma strategies. Can J Psychiatry. 2005;50(12):745-752.

8. Srinivasan J, Cohen NL, Parikh SV. Patient attitudes regarding causes of depression: implications for psychoeducation. Can J Psychiatry. 2003;48(7):493-495.

9. Barney LJ, Griffiths KM, Jorm AF, Christensen H. Stigma about depression and its impact on help-seeking intentions. Aust N Z J Psychiatry. 2006;40(1):51-54.

10. McNair BG, Highet NJ, Hickie IB, Davenport TA. Exploring the perspectives of people whose lives have been affected by depression. Med J Aust. 2002;176 Suppl:S69-S76.

11. Bayer JK, Peay MY. Predicting intentions to seek help from professional mental health services. Aust N Z J Psychiatry. 1997;31(4): 504-513.

12. Komiti A, Judd F, Jackson H. The influence of stigma and attitudes on seeking help from a GP for mental health problems: a rural context. Soc Psychiatry Psychiatr Epidemiol. 2006;41(9):738-745.

13. Hansson M, Chotai J, Bodlund O. Patients' beliefs about the cause of their depression. J Affect Disord. 2010;124(1-2):54-59.

14. Budd R, James D, Hughes I. Patients' explanations for depression: a factor analytic study. Clin Psychol Psychother. 2008;15(1): $28-37$.

15. Highet NJ, Hickie IB, Davenport TA. Monitoring awareness of and attitudes to depression in Australia. Med J Aust. 2002;176 Suppl: S63-S68.

16. Andrews G, Henderson S, Hall W. Prevalence, comorbidity, disability and service utilisation: Overview of the Australian National Mental Health Survey. Br J Psychiatry. 2001;178:145-153.

17. Gabriel A, Violato C. The development and psychometric assessment of an instrument to measure attitudes towards depression and its treatments in patients suffering from non-psychotic depression. J Affect Disord. 2010;124(3):241-249.

18. Coryell W, Endicott J, Winokur G, et al. Characteristics and significance of untreated major depressive disorder. Am J Psychiatry. 1995; 152(8):1124-1129.

19. Hirschfeld RM, Keller MB, Panico S, et al. The National Depressive and Manic-Depressive Association consensus statement on the undertreatment of depression. JAMA. 1997;277(4):333-340.

20. Barney LJ, Griffiths KM, Jorm AF, Christensen H. Stigma about depression and its impact on help-seeking intentions. Aust N Z J Psychiatry. 2006;40(1):51-54.

21. Jorm AF, Korten AE, Jacomb PA, Christensen H, Henderson S. Attitudes towards people with a mental disorder: a survey of the Australian public and health professionals. Aust N Z J Psychiatry. 1999;33(1): $77-83$. 
22. beyondblue.org.au [homepage on the Internet]. beyondblue: the national depression initiative; 2012. Available from: http://www.beyondblue.org. au. Accessed 21 January 2012.

23. Cohen J. Statistical Power Analysis for the Behavioral Sciences. New York, NY: Academic Press; 1977.

24. Blignault I, Chang O, Parker G. Description and evaluation of a project to improve the identification and management of mood disorders in developing countries. Australas Psychiatry. 2010;18(5):460-464.
25. Jorm AF, Christensen H, Griffiths KM. Changes in depression awareness and attitudes in Australia: the impact of beyondblue: the national depression initiative. Aust $N$ Z J Psychiatry. 2006;40(1): $42-46$.

\section{Publish your work in this journal}

Patient Preference and Adherence is an international, peer-reviewed, open access journal focusing on the growing importance of patient preference and adherence throughout the therapeutic continuum. Patient satisfaction, acceptability, quality of life, compliance, persistence and their role in developing new therapeutic modalities and compounds to optimize clinical outcomes for existing disease states are major areas of interest. This journal has been accepted for indexing on PubMed Central. The manuscript management system is completely online and includes a very quick and fair peer-review system. Visit http://www.dovepress.com/ testimonials.php to read real quotes from published authors.

Submit your manuscript here: http://www.dovepress.com/patient-preference-and-adherence-journal 